\title{
Conversations with Writing Center Scholars on the Status of Publication in the Twenty-First Century
}

\begin{abstract}
This chapter synthesizes conversations with seven individuals working prominently within the discipline of writing center studies. It discusses how these scholars conceptualize and define their experiences with Writing Lab Newsletter, Writing Center Journal, and/or Praxis and also reveals their ways of describing the broader significance of digital and open-access scholarship.
\end{abstract}

Keywords Interviews • Writing Lab Newsletter • Writing Center Journal - Praxis $\bullet$ Open-access $\bullet$ Digital literacies

"Steal my book when it's published," says Mark, an assistant professor and writing center scholar. Lamenting the pay walls that often typify academic publishing processes, Mark continues, "there are certain people within writing center studies that are looking at social justice approaches. And if we're putting up this barrier, this lack of access..." before shaking his head sadly. Indeed, the idea that writing center scholars ought to maintain a particular concern for the "social justice issues" involved with publishing is mentioned explicitly or implicitly in many of my conversations with seven interview participants - all individuals with significant experience working in writing centers and/or publishing on writing center topics. For example, Grace, an associate professor and program director, notes that "We have to have more sophisticated ways of sharing our work, and it can't be

(C) The Author(s) 2018

E.H. Buck, Open-Access, Multimodality, and Writing Center Studies, https://doi.org/10.1007/978-3-319-69505-1_5 
exclusively tied to institutions, and I think in a lot of ways it is. And, especially for people who are doing writing center work, that's a problem." The implication here is that not all those who engage with writing centers are able to access resources with attendant barriers, whether that manifests in a lack of institutional subscription to a particular journal, the inability to locate relevant articles, or varying levels of digital literacy. This work has thus far focused mainly on the multiple ways that the digital reveals, complicates, and/or intervenes in writing center publications but, in this chapter, these issues are examined with regard to individual experiences with these publications, as well as for their broader significance for both the discipline of writing center studies and the larger field of composition studies. As such, while the conversations with these intelligent and accomplished individuals were wide-ranging and complex - and the depth of discussion is unfortunately too great to include in entirety here-this chapter describes how these scholars articulate issues of access, affordances, and the ways that the digital might shape the future of writing centers. If there is one argument that this chapter advances prominently, it is encapsulated most succinctly by Grace: "I think we think about ourselves as a community as very inclusive, and I don't know that we really are...we need to take a hard look at how easy or difficult [it is] for certain people over certain other people to get access to the resources that we have for cultivating and maintaining conversation." It is evident that the digital very much facilitates this access, and these discussions help to illuminate the various ways in which admission into one of the most explicit gatekeepers of academepublication-remains a complex and intricate concern.

\section{Methods And Participants}

The seven participants selected for participation in this research provided their consent to be interviewed after taking a survey distributed on the WAC, WCenter, and WPA listservs described in Chap. 2. Of the 184 individuals who completed the survey, 25 provided their contact information after responding to the final survey question that solicited participants with experience in writing center studies. To select participants for an interview, two main criteria were followed for purposeful inclusion: (1) the extent of their previous publication experience, particularly a familiarity with Writing Lab Newsletter, Praxis, and/or Writing Center Journal and (2) a stated research interest in digital studies or multimodality, in addition to writing center experience. Because I relied on Internet searches to ascertain these 
qualities, however, I acknowledge the selection bias that likely occurred as a result (i.e., high digital presence resulted in a higher chance of selection, which perhaps itself reinforces some of the privileges associated with affiliation with a department that promotes individual scholarship on department websites, etc.). From this initial list of 25 individuals, I contacted ten to participate in an interview, and seven of these individuals were ultimately able to schedule and complete an interview. Although several individuals gave permission to include their real names in the publication of this final report, due to the sensitivity of some of the discussion, I elected to assign pseudonyms to all participants, except in a few instances where a participant selected his/her own pseudonym. The list of participants, and their pseudonyms, is as follows:

Grace, Associate Professor and Program Director

Mark, Assistant Professor

Jim, Associate Professor and Program Director

Carol, Multiliteracies Center Director

Susan, Associate Professor and Chair

Kate, Assistant Professor and Assistant Program Director

Bill, Associate Professor and Learning Centers Director ${ }^{1}$

I conducted these interviews via Skype or Google hangouts, and they took place during the months of May, June, and July 2015. They were also semi-structured and lasted an average length of approximately 45 minutes. Since the intent of each interview was to gain insight into each participant's individual experiences, after I briefly described my larger project, the interviewees typically engaged with particular aspects in which they had some experience, with the interview questions (see Appendix 2), providing some structure to the conversations.

It is important to note that just as privilege and perceptions of privilege remain central points of interrogation in this discussion-and privilege was embedded, as previously noted, in the process of initially selecting the participants-all the interviewees also embody positions of privilege within the academy, with the vast majority currently holding tenured or tenure-track positions. Most participants also work at larger, public institutions, which possibly have more institutional support and resources than smaller sites. As discussed in Chap. 2, future empirical research on this topic should specifically seek out those who do not have full-time and/or tenure-track status or those who work within more marginalized contexts. 


\section{Transcription, Data Coding, and Research Questions}

All interviews were audio recorded and then transcribed. Because the process of transcription is necessarily interpretive, the punctuation and grammar of the quotations excerpted here reflect my perception of the interviewee's intent. Since I am interested in their comments thematically, and was not focused on the particularities of linguistic variation, I eliminated fillers (e.g., "um," "like") from the transcripts, and I indicate jumps in conversation with ellipses $(\ldots)$ and pauses with em dashes (-). The interviews were analyzed following Creswell's (2009) suggestions for coding procedures using "topics that readers would expect to find, based the past literature and common sense," and with attention to themes that have manifested already in this project: specific experiences with Writing Lab Newsletter, Praxis, and Writing Center Journal, conversations about access, discussions pertaining to digital affordances, and thoughts on digital future(s) and communities (186). Because of this focus, as well as the need to moderate specific details of projects in order to maintain confidentiality, much fruitful conversation has been left out of this final report. Broadly, this chapter investigated three primary research questions: (1) How do individuals working prolifically within writing center studies perceive prominent writing center publications? (2) How do scholars working in or engaging with writing center studies conceptualize differences in digital and print modes of publication? (3) What might be some of the concerns that scholars specifically have about the current status of publication? Prior to any broader dissemination of this research, the chapter was sent to each participant to ensure that their portrayal here reflected an accurate representation of their words.

\section{EXPERIENCES With WRITING LAB NEWSLETTER, Writing Center Journal, ANd Praxis: A Writing CENTER JOURNAL}

The first focus in these conversations was on how participants perceive the major publications in writing center studies, specifically Writing Lab Newsletter, Writing Center Journal, and Praxis: A Writing Center Journal. Although not all interviewees had experiences as authors in these journals, several have appeared in one or more of the publications. My interest in asking participants about their work in Writing Lab Newsletter, Writing Center Journal, and/or Praxis: A Writing Center Journal was to ascertain 
their perceptions of how these journals differ from each other. A common theme then in these discussions was the relative difficulty of having work accepted for publication in Writing Center Journal. Carol noted that, although she has published pieces in both Praxis and Writing Lab Newsletter, she had recently received a rejection from Writing Center Journal. She, however, praised the editors as "wonderful" and commented that, "I think there's just different types of things that the journals focus on." Susan mentioned that Writing Center Journal is "definitely a prestigious journal," but she also noted, "I don't know if that would be a top journal enough, because it's not really famous outside writing centers. Writing center people know how good it is, and how hard it is to get in, but I don't know if other people do." Jim also suggested that "prestige is a part of it" and considered Writing Center Journal in relation to other publications within writing studies: "I mean, [in] which do I choose to publish? Do I choose to publish and submit my work to CCCs [College Composition and Communication], or College English, or Writing Center Journal? I think that gets complicated for people trying to get promoted and tenure, people with tenure-track positions." The concept that both Susan and Jim seem to imply here-perhaps Susan more explicitly so than Jim-is that, even though Writing Center Journal is typically perceived as the most prestigious journal within writing center studies, it still does not have the same level of credibility as journals like College Composition and Communication or College English. Since tenure and promotion protocols often rely on measures of the journal's impact, again, as Jim notes, scholars must consider these factors when deciding where to submit their work, as an article's focus on writing centers does not mean it falls under the exclusive purview of writing center journals.

Other authors, like Grace, had more specific reasons beyond a journal's perceived prestige for wanting their work to appear in one publication over another. She described an instance in which, having received a revise and resubmit from Writing Center Journal, she and her co-author decided instead to move the piece to a different publication. On this circumstance, Grace commented, "the editors just wanted us to do work that was going to take us in a direction that we didn't think was necessary, and we could see this really prolonged publication process, and so we went over to Praxis and it was really smooth and came out really quickly." Kate also expressed that turnaround time factored heavily in her experiences with Writing Center Journal: 
I mean [my piece in $W C J]$ must of taken so, so long to come out, probably two- and-a-half years...And we got great feedback from the peer reviewers, and we made substantial changes, but it was an incredibly long period of time. And...even though it's the most prestigious journal, it made me think long and hard about whether or not to submit with them again because it just took so long for something to come from start to finish, from submission to the final print [version].

This response is interesting because it illuminates another factor of the tenure and promotion process that may supersede a journal's prestige. Although Kate also praised the WCJ peer reviewers, "fantastically useful feedback" and "really helpful" comments, she notes the importance, like Grace, of time to publication.

These factors, associated in this case with Writing Center Journal, speak to other qualities of a journal that shift over time and demonstrate the complexities of producing a peer-reviewed publication. A journal's editor(s), while certainly playing a large role in the referee process, typically do not retain sole culpability for the production of a journal. In one instance though, a participant ${ }^{2}$ did seem to view a particular editor as having a great deal of influence on the character of the journal, noting that they, "had a really bad experience with Writing Lab Newsletter." The author describes that, after receiving complex feedback from a peer reviewer who "really wanted us to situate things within the broader scholarly conversation," they made significant revisions only to have the editor reject many of the changes. The participant commented that "we did all of that work, and then [the journal's editor] basically said take all the theory out. And so, what are you going to do? We sat with it for long enough with that journal that we didn't want to kill it, but it was really tempting." What this participant indicates here, and what other interviewees echoed, is the perception of Writing Lab Newsletter as a journal with a different philosophy than Writing Center Journal and Praxis - a philosophy that emphasizes heuristics over theory. And yet, for a scholar like Bill, Writing Lab Newsletter's focus was very much a positive attribute of the publication. Bill indicated that he published an article in Writing Lab Newsletter because "I actually want to reach practitioners." He believes that the readership is wider for Writing Lab Newsletter than it is for Writing Center Journal, and his decision to submit to the former was motivated by his understanding that, "there's a ton of theoretical underpinning to the work that I do, but it's not as important as operationalizing and changing best practices." Given Writing Lab Newsletter's ongoing transition to WLN: A Journal of Writing Center 
Scholarship - a name change that surely signifies heightened gravitas-a shift in focus away from "best practices" would likely result in more ready comparisons to Writing Center Journal and Praxis. A journal's identity, built by its current editor(s), its review process, and its overall perceived focus, will impact the kinds of submissions that it receives and, as illustrated by the above comments, the decision to continue to contribute to a specific publication.

A final point regarding these three journals also speaks to the significance of a publication's concentration and juxtaposes readily with the perceived purpose of Writing Lab Newsletter. Specifically, several of the participants commented on Writing Center Journal's explicit and ongoing focus on RAD research (i.e., research that is replicable, aggregable, and data-supported). On this point, Mark commented that "With the Writing Center Journal...they made a conscious effort to push writing center studies toward doing Haswell's idea of RAD research within writing centers. And so they're making a concentrated effort to privilege scholarship that does that sort of quantitative- that sort of reproducible types of scholarship." While Bill saw this push toward RAD research as the kind of work that will "bring some ethos to what we do," Kate spoke of a colleague who "[thought] that we made the turn too hard into RAD research." Although she classifies herself as more of an "empirical person," she wonders about what is lost in this shift: "It would be good if we could move a little bit away from anecdotal work, but there is a lot to be said about the lore, right?" This "theory versus praxis" binary is often characteristic of writing center and administrative scholarship, and it is a divide mentioned not infrequently within writing center discourses. ${ }^{3}$ But it is also worthwhile to note how perceptions of this binary seem to correlate with Writing Lab Newsletter on one side (praxis) and Writing Center Journal on the other (theory). On Praxis, Mark suggested that "if we want Praxis to be a thing that's valued, then people need to start reading it and using it in their scholarship." The same principle is true for Writing Center Journal and Writing Lab Newsletter as well, but the extent to which these journals can be read and used depends very much on their respective (digital) affordances.

\section{ACCESS AND AfFordances}

In this section, my emphasis in the conversations with participants was on the ways in which they conceptualize the digital mechanisms of publication and those digital tools that impact a journal's reception. In some cases, these conversations pertain specifically to Writing Lab Newsletter, 
Writing Center Journal, and Praxis: A Writing Center Journal, but they also extend more broadly to digital publications or the extent to which a publication maintains a digital presence. One topic mentioned frequently was Writing Center Journats lack of web availability. Grace noted that since her institution stopped paying for a digital subscription, it has been increasingly difficult for her to access the content that she needs for her research. "We've stopped getting the electronic version," Grace indicated, "I've gone to [Writing Center Journal's] website, and first of all the website is horrible, ${ }^{4}$ it took me a long time to even find the table of contents for the most recent issue so that I could request articles from my interlibrary loan [system]." She later reiterated that "The fact that I couldn't get access to the table of contents, much less the article itself, online though the Writing Center Journal website- that was very frustrating." Speaking about the Writing Centers Research Project-once housed at the University of Louisville and now operating out of the University of Arkansas, Little Rock-Susan questioned why all the Journals archives were no longer available through this resource, suggesting that "The online presence or the online repository of the Writing Center Journal really has been a problem-because now, it's, to tell you the truth, it's terrible-not all the articles are there, it hasn't been updated in, I don't know, maybe ten years or eight years." Because Writing Center Journal remains the most traditional of the venues for writing center scholarship in that its primary mode of publication is the print format, it again readily juxtaposes with Writing Lab Newsletter (whose website houses most past issues as accessible PDFs) and Praxis: A Writing Center Journal (an entirely open-access digital publication). Kate, however, considered how the inability to easily access Writing Center Journal online impacts both her teaching and her research practices. "I have to say that as a researcher my first tool is often Google Scholar," she noted, "and you can sometimes find the Writing Center Journal articles there, but nobody's citing them and there's no access to them." Kate also suggested that, when she teaches her tutor training course, "because the archives for Writing Lab Newsletter and Praxis are so accessible, a lot of the stuff that [the students] get comes from there." Yet, when Kate directs her students to articles from Writing Center Journal, "they'll be like, 'how do I get that?' And I'm like, 'Interlibrary loan it and it'll take two days.' But for an undergraduate student that feels like too much for them to grapple with."

In these instances, Kate also grapples with the complexities of Internet tools (such as Google Scholar and institution-supported databases) that 
tend to privilege certain types of research over others. For this reason then, these digital search tools-and what content they point users tofactors importantly into this conversation. Bill discussed the significance of indexing these journals in prominent research databases and the role that this process plays in terms of facilitating access: "There's definitely a place for Writing Center Journal, but I think it's less accessible, and not just because it's a pain in the ass to search though the old editions online, it is. But actually...none of the writing center stuff is very well indexed. The big journals, like NCTE, are all indexed." One participant, who has experience indexing journals for a large database, noted that access also plays a role in the ability to initially index materials. This participant suggested that "the problem I run into is accessing the copies. So, I also index forward in time and I index back in time, [and it's difficult] because nobody indexed all of Writing Lab Newsletter and Writing Center Journal-from the very beginning nobody indexed it." This participant also noted that it was easier to complete this indexing when Writing Center Journals archives were more accessible through the Writing Centers Research Project, "but after that got taken down, it's really been difficult for me to get the issues. I don't think people understand that I need the issue. I don't care if it's print or digital, but if it's digital, it's got to be a PDF, it can't just be random articles." Jim expressed even more specifically the ways in which indexing, especially for writing center publications, remains a complex process:

There's a fair number of efforts to try to get Writing Center Journal to show up in the [database] systems - the big ones that people have to pay for, just like JSTOR. But I don't think it is in JSTOR. ${ }^{5}$ Because that's expensive... [the lack of citations for Writing Center Journal] is partially because when you do a search, even in Google Scholar, Writing Center Journal might not show up. So how is it going to get cited if people aren't going to find it in their bibliographic work? You have to do a very specific, "Oh, I'm writing a writing center article, I'm going to go to comppile because I know all the writing center articles will be there." I don't know if it sounds like a simple problem, but it's a really complex problem. Well, it's a simple problem with a complex solution. Getting increased access in kind of those high volume databases - if it were easy, we would have done it a long time ago.

The database Jim references here, comppile.org, is a freely accessible service for locating articles pertaining to writing studies-related subjects. But searches on comppile.org require some prior knowledge of a topic - and 
comppile's specific search terms - as the engine's algorithms are not as sophisticated as those of the "high volume" databases like JSTOR. These perspectives thus reveal the ways that the complexities of digital access constellate in the indexing of articles: if articles are not easily accessible for indexers, then the content is much less likely to be indexed, thus increasing the likelihood that articles may not be cited as frequently and/or that databases may altogether exclude digital texts. In some ways as well, the journals themselves also participate in this process through their citation patterns, which is an argument that has been explored in recent writing center scholarship. ${ }^{6}$ On this point, Mark observed that "you'll see less citations in Writing Center Journal of things like Praxis, of things like Writing Lab Newsletter...now is this a factor of them being digital journals, and so these print ones don't want to cite from digital journals? Maybe."

Even if something like Writing Center Journalor Writing Lab Newsletter is eventually indexed in JSTOR, ${ }^{7}$ as Jim points out, this database is expensive and likely inaccessible to those without an institutional affiliationand sometimes also to those with such an affiliation as well. Grace's experiences reinforce this: "What [the editors of Writing Center Journal] have done is created a little paragraph where they say that WCJ is available through these following databases, well we don't have [them], and we have a pretty robust set of databases, but we don't have any of those that they listed." A purely digital archive of journal materials is not necessarily a panacea either, for reasons having to do with both the archive's overall navigability and stability. Grace commented, Writing Lab Newsletter's archive "is so weird," and that, "it seems like the search system that they have-well, it pulls up everything. And I haven't really been able to find a way to narrow that." Susan also commented on the fact that Praxis's archive of former issues is missing some content- "there are some issues of Praxis that are just gone." She later reiterated that "that's a problem with this online stuff-there has got to be some stability to the archives, because people need to find these articles. And they used to be there, and now 'poof' they're gone, or they're not there in a format that can be accessible - then, it's frustrating for people." Susan recommended that strictly online journals "should print out a copy somewhere, and put it somewhere, some kind of archive-physical," but she also wondered "then what do you do with a video?"

This question transitions into another important facet of digital composing - the production and distribution of multimodal scholarship. Susan was perhaps particularly aware of this issue because she participated 
in the creation of a video composition, and wondered about its possible fate, should "the server explode or whatever," noting that "hopefully [the video will] be stable enough that it will actually be there and not disappear and go away." For the other interviewees, very few of whom had experiences composing multimodal and/or digital texts, their reasons for avoiding these compositions also reveal broader concerns about engaging in new media scholarship. There particularly seemed to be some resistance to creating these texts because of perceived generational differences. Grace, for instance, indicated that when she looks at a digital journal "because I didn't grow up reading digital texts, when I go to something like Kairos, I'm just looking for a PDF. The idea of slogging through, because that's what it is for me-it's not what I'm used to, or what I grew up doing." She later suggested that this might be one reason for why others avoid digital texts in their research, commenting that "I know [that these processes are] generational, but nonetheless, it's bound to shape what sources we draw from and what sources we don't draw upon and that kind of thing." Jim also expressed that his ways of interacting with texts shape how he approaches his projects and possibly his rhetorical choices: "If I was going to publish [a piece] in Kairos or some sort of online journal, what would I be able to do that I can't do in print? I never really thought that way because I think I'm just too old school to think about it." These perspectives then are important because they reveal the ways in which perceptions of digital texts possibly contribute to the continued perpetuation of print forms of research.

This is not to suggest that Grace and Jim do not consider these resources important, but just that the digital is not the medium through which they feel most comfortable composing or reading in. Jim also implied that this is why Writing Center Journal continues to publish in a print format. He explains, "there's kind of a familiarity and comfort with a print version that I think as scholars we like-to be able to have your hands on something and be able to write on it, and highlight it, and all the rest...there are tactile reasons for wanting a print version." Mark, however, points out that this familiarly - this tendency to perpetuate the status quo-could have several important implications, especially in terms of giving authors the freedom to determine the best way to present an argument. He suggests that digital texts "[allow] the authors to physically arrange the content, the visual content, the textual content, audio, video, whatever they incorporate in there... Whereas obviously the more traditional print journals [don't]. There's an accepted, 'this is the best way to present the content 
and so therefore all the content should be presented this way." In either case, these perceptions reveal some of the intricacies associated with engaging with digital forms of scholarship. Although these researchers in many cases acknowledge the particular (and often advantageous) affordances of the digital, there is still an ongoing perception, as Bill notes that "a lot of it also has to do with the age of people engaging with [the digital]." If a prevailing view is that only young scholars, or scholars that have taken a particular interest in this work, connect with digital publications, then it is unlikely that the arguments about the value of digital work will perpetuate beyond target audiences. Mark illustrates this point concisely:

If the only articles that we can find that are talking about why Twitter use by writing centers is effective are on digital publications like Kairos or Praxis, then the types of people who don't already value those types of publications aren't going to be persuaded....as rhetoricians we want to the form to reify the content in sort of a self-recursive way, but then if it's one of those things that doesn't appeal to the audience you're working with, that's not going to work.

In consequence, issues of access are not just measured by the ability to find and read texts online, but on one's motivation to read and engage with these texts. This is a complex situation for a number of reasons, but it also becomes significant for its role in building and maintaining larger writing center communities, where digital access-in all its manifestations-is a critical factor.

\section{Digital Communities/Resistance}

A final concentration in these conversations was on how the digital can help create and facilitate communities of writing center scholars, and also on what the digital might mean for writing centers as sites of research and learning. While multimodality does not always signify something that is digital, because these two concepts often correlate and inform each other, discussions about what role multimodality can or should play in writing centers became a focus. "The future of writing centers has to involve multimodality," Grace argued, "because whether we're doing it or not, other people are, and if we are going to position ourselves as the place where writers can go to talk about the rhetorical issues that attend to multimodality, then we've got to know about it." For Carol, who directs a multiliteracies center that exists separately from her campus's writing center, 
this question of where multimodality/multiliteracies fit within writing center discourses is a concept she must confront frequently. Because of her background in writing center studies, Carol noted that "a lot of the scholarship I'm going to draw from is from the writing center field, it's just natural for me, and that translates very well." Some writing center researchers, however, are not always receptive to defining her center's work as within the purview of writing center studies. Carol recalled instances in which she would respond to research requests only to have the researcher(s) ask her not to contribute. She explains,

Most of the time [interactions with researchers are] very positive, but I have had researchers tell me, "No please don't answer this survey, what you're doing is a little different, and we mean 'writing centers' in this sense."...So, if I'm talking about my center itself, not the research that I do, but the studio, I'll always make sure that I ask, but it's kind of a shame that I have to ask in the first place, right? And, as I said, I have had researchers say, "no, that's not what we mean by writing center, I appreciate your asking." You know, they're always very polite about it, but they'll tell me not to participate.

Carol's anecdote reinforces continuing resistance to broadening the definition of writing center studies to embrace multimodal work, which impacts the extent to which Carol can claim affiliation as a professional within a writing center community.

Scholars like Jim and Bill also refer to how the professionalization of writing center leaders contributes to the ways that communities are formed. Jim noted that "For every job that we see that someone's looking for a tenure, tenure-track writing director, there's another one in which they're not." Bill suggested that many of these directors will not be as well-versed in writing center theory as those who have degrees in writing studies, commenting that "those people [without degrees in writing studies] are doing great work, but they haven't been professionalized to do scholarship, they haven't been trained to do research." For this reason then, their ability to access research becomes even more crucial. In a perspective similar to that of Mark's at the beginning of this chapter, Grace sees this issue as specifically tied to social justice concerns, as "I do think the question about access has emerged and will continue to emerge and if we really want to be true to the kind of diversity that we say that we're interested in." She also suggests that "[if] 
we're not just interested in people who have PhDs in writing studies and who are tenure-track writing center professionals, then we're going to have to think about being creative with access, because those people are being isolated in some ways."

Grace ultimately describes scholars like Kate, whose $\mathrm{PhD}$ is in a field very different from those typically associated with writing center studies. On first receiving a directorial position in a writing center, Kate suggests that she was hired because she had experiences teaching writing and tutoring, but she noted that "I think it speaks to the status of the field that as professionalized as it might be, [my] position was initially a staff position, although now it's a faculty position." Kate describes how her writing program administration was instrumental in encouraging her to participate in the writing center community through scholarship. She was "very insistent that if I wanted to continue in this field and not have this be just a random job, that it was important that I do research." The insight of this particular WPA on the importance of scholarship to gaining entrance to a community is key and perhaps informs Kate's position on open-access research. As a frequent attendee at international writing center conferences, Kate describes the importance of accessibility to facilitating global writing center communities:

The people that I was talking with [at an international conference], they in particular really need digital access to things...We're a community of collaboration, right? And so the idea that some things are kind of hidden by a wall...I understand the importance of publishers and not making necessarily everything completely open-access, but you've got to make it easier for people to get to [research]. And talking with people at this conference, they were all kind of saying that having things free and open-access made them use it, and if they can't use it-like if you're the only writing center in Afghanistan-then you don't have someone that you can call. You have an Internet connection.

Kate brings up a key point here in that, if writing centers are theoretically built upon "communities of collaboration," then a lack of open-access seems to run counter to this philosophy. Although many interviewees were concerned about whether individuals outside the tenure system could gain access to writing center research and communities, Kate demonstrates that there are audiences outside of the United States that also rely, even more critically, on the ability to find and use these resources. 
There are other digital tools beyond scholarship that also work to build communities of writing center scholars. One of these tools is the Wcenter listserv. Susan was particularly enthusiastic about Wcenter as a digital community and spoke frequently of the connections that she has made on the platform, including meeting scholars who ultimately became co-authors: "a lot of the people that I've written with-I've met through Wcenter. Made contact with them, started to write, and then never met [physically] until years after." She also suggests that Wcenter can be a way to move around some of the obstacles of access, arguing that "every so once in a while will write on Wcenter and say, 'does anyone have this article?' People will have a PDF on their own computer and they'll send it. So there's sort of like a network of self-archiving that's happening too [on this platform]." While Wcenter is a wonderful resource for creating communitiesit is perhaps one of the best examples for how Internet networks can work specifically to combat some of the barriers of access-it is also something that is difficult for those on the periphery to locate. Mark addresses this point when he argued that "if you're on the inside, if you are a stakeholder who is already connected with the people doing the work, those connections tend to stay really well. But as a discipline we don't do a great job of reaching across there." The efficacy of these digital resources depends on individuals' ability to successfully locate them and understand their uses, purposes, and conventions. Again, for those already invested in the community, digital groups such as Wcenter are superb assets, but these tools do not necessary correlate with universal accessibility or support.

\section{Conclusion: Intricacies of AcCess}

When I concluded discussions with the participants, several indicated their hope that this project would help to facilitate improved accessibility, especially for those outside of standardized and/or institutionally legitimated writing center communities. Grace argued that "even if it's technically true that people in those [other] sites can eventually get access to documents through a variety of means...it's still not making it very easy for people to have a conversation and to understand what conversations are taking place." One interviewee noted that a possible solution would be for "a group [to] get together and just write a grant," especially to help make Writing Center Journal more accessible through the Writing Centers Research Project. Another suggested that writing center tutors could also be involved in this process, as "there's a whole army [of tutors] nationally 
who are being paid sitting around waiting for people to come in-why don't we break down the [WCJ] archives and have them index the whole thing, and run it as a big collaborative project? It would be an awesome thing to do." These would both be very beneficial steps and, indeed, could be feasibly enacted. Yet, it is my hope that this chapter also illustrates the complex and highly interconnected processes involved with increasing all forms of digital-mediated access. This access may manifest in perceptions of Writing Lab Newsletter, Praxis, and Writing Center Journal, the availability (or a lack thereof) of these journals' attendant online resources, and views on digital work in general, as well as what relationship the digital should have to writing centers. All of these concepts have significant bearing on the ways that individuals facilitate and conceptualize entrance into writing center communities.

There might also be some benefits to the current system, as Carol suggested, “I don't think there's anything wrong with Writing Center Journal staying mainly a print journal. You know, it can be an access issue, but I think also part of the hope is that people will subscribe and also become members of IWCA [the International Writing Center Association]." In the most ideal situation though, everyone who wanted or needed to have access to writing center research would be able to do so at a free or affordable rate. As some of these conversations illustrate, the complex process that is digital literacy acquisition is also critically important to this topic. Writing Center Journal's indexing on a database like JSTOR still depends on the searcher's ability to traverse JSTOR's navigational features, which is neither a simple nor a straightforward process. Making Writing Center Journal more accessible, while something that would be highly advantageous for many individuals, is not necessarily enough: these issues are so intertwined in a multitude of different processes and systems, many of which are deeply embedded in and as ideologies of academe. For example, as important as what was said in the interviews, what was not said is equally telling. It was surprising how infrequently the participants mentioned Praxis, even though I explicitly identified that this journal was one of my research artifacts. Mark's comment that "if we want Praxis to be a thing that's valued, then people need to start reading it and using it in their scholarship" is acutely appropriate-not only do people need to read it and use it in their scholarship, they also need to talk about it. Aside from Mark's comments, the only other participants who specifically mentioned Praxis were Susan (who commented disparagingly on Praxis's missing archives), Grace (who reflected on her positive experience publishing with 
the journal), and Kate, who also commented on her positive experience as an author in the journal and on Praxis's larger accessibly (i.e., "it's so much easier to search for things in Praxis and WLN or other online journals"). Again, this seems particularly telling. The only individuals who commented enthusiastically on Praxis-aside from Mark-were those that had experiences publishing in the journal. ${ }^{8}$ Susan's comment implies that Praxis becomes more visible only when something is amiss, suggesting a perception that innovative journals will be subject to additional scrutiny. The fact that so much of the conversations revolved primarily around Writing Center Journal or Writing Lab Newsletter is particularly demonstrative -it reinforces the idea that, as Mark noted, only those who already engage with these new forms will likely be conscious of their value. Writing center studies faces a significant challenge in terms of widening the visibility not only of writing center studies broadly, but as related also to up-andcoming publications like The Peer Review that experiment with new forms. The more that writing center scholars can to do reach out to others via these innovative mechanisms, however-especially to those outside of institutionalized systems - the more inclusive the conversation will ultimately be.

\section{Notes}

1. I recognize that these pseudonym choices likely reflect specific racial and gender identities and, while it is my intent to represent these participants as authentically as possible, naming is inevitably a politicized act. As such, to the extent that identities can be ascertained through interviews of this nature, I believe that these pseudonyms also reflect the larger homogeneity within the academy.

2. Because of the particularly sensitive nature of this criticism, I will refer to this participant without their pseudonym and its attendant gender signifier.

3. See Driscoll and Perdue (2012), for a recent perspective.

4. Note: Writing Center Journal did implement some changes to their website in Feb. 2016, although there still are no tables of content from previous issues included.

5. It should be noted that, in September 2015, Writing Center Journal was added to JSTOR. However, this extent of access depends on the institutional subscription. At one of my institutions, for instance, only the titles and abstracts of $W C J$ articles are accessible on JSTOR. 
6. See Lerner (2014).

7. Again, it ultimately was indexed in JSTOR in Fall 2015.

8. And one participant, Carol, who did publish in the journal, did not comment specifically on her experiences-she instead discussed her rejection from Writing Center Journal.

\section{Works Cited}

Creswell, John W. 2009. Research Design: Qualitative, Quantitative, and Mixed Methods Approaches. Los Angeles: Sage.

Driscoll, Dana, and Sherry Wynn Perdue. 2012. Theory, Lore, and More: An Analysis of RAD Research in The Writing Center Journal, 1980-2009. Writing Center Journal 32 (1): 11-39.

Lerner, Neal. 2014. The Unpromising Present of Writing Center Studies: Author and Citation Patterns in The Writing Center Journal, 1980 to 2009. Writing Center Journal 34 (1): 67-102.

Open Access This chapter is licensed under the terms of the Creative Commons Attribution 4.0 International License (http://creativecommons.org/licenses/ by $/ 4.0 /$ ), which permits use, sharing, adaptation, distribution, and reproduction in any medium or format, as long as you give appropriate credit to the original author(s) and the source, provide a link to the Creative Commons license and indicate if changes were made.

The images or other third party material in this chapter are included in the chapter's Creative Commons license, unless indicated otherwise in a credit line to the material. If material is not included in the chapter's Creative Commons license and your intended use is not permitted by statutory regulation or exceeds the permitted use, you will need to obtain permission directly from the copyright holder.

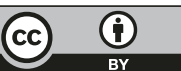

